\title{
Energy Expenditure and Body Composition in Preterm Newborns with Bronchopulmonary Dysplasia at Term Age
}

\author{
Paola Azara Tabicas Lima \\ Instituto Fernandes Figueira \\ Maria Dalva Barbosa Baker Méio ( $\nabla$ mdbakermeio@gmail.com ) \\ Instituto Fernandes Figueira https://orcid.org/0000-0002-7290-9091 \\ Maria Elisabeth Lopes Moreira \\ Instituto Fernandes Figueira \\ Andrea Dunshee de Abranches \\ Instituto Fernandes Figueira \\ Bruna Grazziotti Milanesi \\ Instituto Fernandes Figueira \\ Saint Clair S Gomes-Junior \\ Instituto Fernandes Figueira
}

\section{Research Article}

Keywords: preterm, bronchopulmonary dysplasia, resting energy expenditure, growth, body composition

Posted Date: November 15th, 2021

DOI: https://doi.org/10.21203/rs.3.rs-1064500/v1

License: (c) (i) This work is licensed under a Creative Commons Attribution 4.0 International License.

Read Full License 


\section{Abstract}

A cross-sectional study was carried out in a cohort of newborns with less than 32 weeks of gestational age. We aimed to evaluate and compare resting energy expenditure (REE) and body composition between newborns who did or did not develop bronchopulmonary dysplasia. The resting energy expenditure and body composition were assessed at the corrected term age using air displacement plethysmography. Anthropometric measurements (weight, head circumference, and length) were performed and transformed into Z-scores per the Fenton curve (2013) at birth and corrected term age. Forty-two newborns were included, of which $26.2 \%$ developed bronchopulmonary dysplasia. Newborns with bronchopulmonary dysplasia (BPD) had significantly higher energy expenditure at corrected term age, with no differences in body composition between the two groups. Conclusion: Newborns with bronchopulmonary dysplasia had higher resting energy expenditure at the corrected term, with no difference in body composition compared to those who did not develop bronchopulmonary dysplasia.

\section{What Is Known}

More significant resting energy expenditure impairs the growth of newborns with bronchopulmonary dysplasia.

\section{What is new}

Newborns with bronchopulmonary dysplasia had higher resting energy expenditure at corrected term age, with no difference in body composition compared to those who did not develop bronchopulmonary dysplasia.

\section{Introduction}

Despite improved neonatal care, bronchopulmonary dysplasia (BPD) is highly incident, especially in extremely preterm newborns [1]. There is great concern regarding the growth of this population, as newborns with BPD have higher resting energy expenditure (REE) required for breathing [2]. Furthermore, very low gestational ages, restricted intrauterine growth, disease severity due to several immature organs and systems, and difficulties in caloric supply affect the adequate nutritional intake, which, associated with higher energy expenditure, compromise the growth of this population [3].

Currently, growth assessment is not restricted to determining standard anthropometric measurements such as weight, length, head circumference (HC), and BMI. The qualitative assessment of body mass, separating the components of fat and lean mass, may reflect the biological and evolutionary changes during the development of NBs $[5,6]$. While lower lean mass has been reported in the population of preterm NBs with BPD $[7,8]$, in a more recent study analysing growth and body composition through air displacement plethysmography in preterm NBs with gestational age (GA) less than 32 weeks with and without BPD, researchers found no statistically significant differences regarding growth and body composition between groups at one month corrected age [9]. 
Higher REE was reported in ventilated newborns [10-12]. Bauer et al. (2003) [13] and Bolt et al. (2006) [2] reported that NBs developing BPD have higher REE than NBs without BPD. This increased REE would contribute to the growth deficit in this population. We did not find more recent reports of REE assessment in this population, and current nutritional protocols advocate greater protein-calorie intake [14-16]. BPD is a multifactorial disease related to lung development, influenced by the nutritional intake after birth [17, 18]. Thus, it is crucial to assess whether the REE in this population was modified by the nutritional changes or there would be an influence on the body composition of newborns with BPD.

The hypothesis for this study was that NBs with BPD would have higher energy expenditure than their peers without BPD, which would be reflected in body composition at term corrected gestational age (CGA). Thus, this study aimed to evaluate REE and body composition, using air displacement plethysmography, in preterm NBs with GA less than 32 weeks at term CGA, comparing the two groups that developed BPD or not.

\section{Methods}

Study design and location: Cross-sectional study in a prospective cohort of preterm NBs followed up in the project "Analysis of Growth and Body Composition in Preterm Newborns with Bronchopulmonary Dysplasia", approved by the Institution's Ethics Committee under Opinion $\mathrm{N}^{\circ} \mathrm{CAAE}$ 50243615.0.00005269. The study was carried out at the Fernandes Figueira National Institute of Women, Children, and Adolescent Health/FIOCRUZ (IFF/FIOCRUZ). The NBs were admitted to the Neonatal Intensive Care Unit (NICU) and followed up at the Follow-up Clinic after hospital discharge. Newborns were only included in the study after the consent of the legal guardians and signing the Informed Consent Form.

Participants- sample size: This study used a convenience sample, including all NBs with less than 32 weeks of GA born between April 2018 and April 2021, admitted to the NICU of the IFF/FIOCRUZ, and followed up after hospital discharge. Those with congenital disabilities, proven congenital infections, genetic syndromes, foetal hydrops, and inborn errors of metabolism were excluded. In this study, REE and body composition in the full-term CGA were evaluated, and anthropometric measurements (weight, length, and $\mathrm{HC}$ ) were performed at birth and at term CGA. The newborns were separated into two groups: the NBs who developed BPD and those who did not develop BPD during hospitalization. BPD was defined as the need for oxygen at 36 weeks of corrected age, requiring any ventilatory assistance [19].

Energy expenditure assessment: The REE was calculated by indirect calorimetry (Deltatrac II® Metabolic Monitor, Datex-Ohmeda, Finland), which allows the measurement of oxygen consumption and carbon dioxide production using a continuous flow generator. Individual energy production is calculated from the energy equivalents of the oxygen consumed, and the carbon dioxide produced, using the Weir equation [20]. The equipment was calibrated before the onset of the study with the alcohol burning test, according to the manufacturer's specifications. The calorimeter was warmed up for 30 minutes before each test and then calibrated with a known gas mixture containing $5 \%$ carbon dioxide $\left(\mathrm{CO}_{2}\right)$ and $95 \%$ oxygen $\left(\mathrm{O}_{2}\right)$. The 
hospitalized NBs were assessed in the NICU. The newborns were in room air and placed in a heated incubator in a thermoneutral zone, monitoring heart rate and oxygen saturation. Newborns discharged before term CGA were assessed at the Nutrition Laboratory linked to the Clinical Research Unit of the IFF/FIOCRUZ. These NBs were placed in cribs in a silent room, with dim light and ideal temperature to maintain the newborn's axillary temperature in a thermoneutral zone (axillary temperature $36.5^{\circ}-37^{\circ} \mathrm{C}$ ) [21] measured at assessment. The newborns were placed in the prone position before the examination for greater comfort, benefiting sleep and inducing less movement. For the examination, a bell was placed around the face of the NB, breathing spontaneously. Measurements were performed for 40 minutes [22], starting one hour after diet administration to minimize the effects of postprandial thermogenesis. The Deltatrac II Metabolic Monitor records minute-by-minute $\mathrm{VO}_{2}, \mathrm{VCO}_{2}$, energy expenditure, and respiratory quotient. Their means and standard deviations are obtained at the end of the exam.

Body composition assessment: Body composition was measured using air displacement plethysmography (PEA POD® Infant Body Composition System, COSMED USA, Inc., Concord, CA, USA). The child should be clinically stable for the examination, and no medication sedation is required. It is placed bare inside a fiberglass chamber attached to a computer and can be observed through the viewfinder. The chosen method for assessing body composition in this study, air displacement plethysmography, follows the classic two-compartment model, that is, it divides body mass into fat mass and lean mass. It estimates body composition through its density, using an equation already entered in the program. It is a non-invasive and easy-to-perform technique.

Growth assessment: Growth was assessed by anthropometric measurements of weight, length, and $\mathrm{HC}$ at birth and term CGA. The birth weight was measured on the incubator scale of each NB (FANEN® Vision Advanced 2286 or Giraffe ${ }^{\circledR}$ Omnibed, with a precision of 4 and 10 grams, respectively) and the weight of term CGA by the plethysmography device. The $\mathrm{HC}$ was measured with an inextensible tape, adjusted to the NB's head, passing posteriorly through the occipital prominence and anteriorly through the supraorbital region, just above the eyebrows. The length was measured with an anthropometric ruler suitable for measuring lying down: the child was placed on a flat surface, and one evaluator positioned his head on the fixed end of the ruler while the other evaluator extended his leg and brought the heel to the mobile base of the ruler. The anthropometric measurements were transformed into Z-scores, using the Fenton curve (2013) [23] as a benchmark.

Nutritional assessment of water, caloric, and macronutrient intake: The number of nutrients received during the NB's first four weeks of life was calculated using the medical prescription and the daily document completed by the nursing team. Information on the volume and composition of parenteral nutrition, volume and concentration of intravenous hydration with glucose serum, and the type and volume of enteral diet, were recorded in a Microsoft Excel 2010 spreadsheet previously validated for a population similar to the one in this study, recording the daily diet administered [24]. The energy and macronutrient composition of the human milk offered are already included in the calculation sheet, provided by the hospital's human milk bank, which performs the analyses using spectrophotometry (Infrared Analysis, Milko-Scan Minor 104®, Foss, Denmark). The calculation of nutrients received by 
enteral diet, consisting of specific milk formula for preterm NB, and human milk fortifier, is made from the information on the product label. In the end, the spreadsheet provides the fluid $(\mathrm{ml} / \mathrm{kg} / \mathrm{day}$ ) and caloric ( $\mathrm{kcal} / \mathrm{kg} /$ day) rates and the amount of protein ( $\mathrm{g} / \mathrm{kg} /$ day), lipids $(\mathrm{g} / \mathrm{kg} / \mathrm{day})$, and carbohydrates $(\mathrm{g} / \mathrm{kg} /$ day) received daily and their weekly average.

Nutritional therapy indicators: The indicators considered were time to start the enteral diet, time to reach complete diet, when the diet volume reaches $120 \mathrm{ml} / \mathrm{kg} /$ day, and time on total parenteral nutrition (TPN). The time of each indicator was computed in days.

Perinatal variables: Pre and perinatal variables were obtained through data registered in medical records and recorded in a standardized information collection form. The gestational information was arterial hypertension, delivery type, twinning, and use of antenatal corticosteroids. Perinatal information included: GA in full weeks (ultrasound up to 12 weeks, date of last menstruation (LMP), Ballard neonatal examination, in that order), gender, APGAR $1^{\text {st }}$ and $5^{\text {th }}$ minute, classification of newborns at birth as adequate for gestational age (AGA) - [Weight Z-score between $\geq-1.28$ and $<1.28$ standard deviations], and small for gestational age (SGA) - [Weight Z-score $<-1.28$ standard deviations], using the Fenton curve (2013), resuscitation manoeuvres in the delivery room, hyaline membrane disease (HMD), surfactant use, ventilatory assistance received (invasive mechanical ventilation (IMV) - and non-invasive mechanical ventilation (NIMV), nasal CPAP, Oxyhood, and nasal oxygen catheter), use of methylxanthines, confirmed sepsis (positive blood culture), patent ductus arteriosus (PDA) and BPD (oxygen requirement at 36 weeks of CGA).

Statistical analysis: The database was created using the Epi Info program, version 7, and the data were analysed using the SPSS statistical package, version 23. The descriptive analysis was performed to estimate the frequency of occurrences, identify patterns and analyse data discrepancies. We calculated the means and standard deviations of continuous variables and frequencies of categorical variables. $\mathrm{GER}, \mathrm{VO}_{2}, \mathrm{VCO}_{2}$, lean mass percentage and volume, fat mass percentage and volume, anthropometric measurements, and their Z-scores in term CGA were compared between NBs with and without BPD. ANOVA statistic was used for continuous variables with normal distribution, or the non-parametric MannWhitney test, when appropriate, considering the p-value of 0.05 as significant.

\section{Results}

During the study period, 114 newborns with GA less than 32 weeks were admitted to the NICU (Figure 1), including 42 newborns who met the inclusion criteria. Of these, 11 NB (26.2\%) developed BPD. We observed $50 \%$ of twinning, $9.5 \%$ of SGA newborns, predominantly by caesarean section $(64.3 \%)$.

The characteristics of the newborns who developed BPD or not are described in Table 1. A higher frequency of invasive ventilation and surfactant use was observed among the newborns who developed BPD. We did not identify any difference in gestational age between the two groups, but newborns with BPD had a greater need for resuscitation in the delivery room, spent more time on oxygen, and made 
greater use of methylxanthines. While we did not detect any difference in the time of starting enteral feedings and TPN use, NBs with BPD took longer to reach complete diet. 
Table 1

Comparison of perinatal, demographic, anthropometric and nutritional support variables between newborns with and without bronchopulmonary dysplasia

\begin{tabular}{|llll|}
\hline & BPD (-) n= 31 & BPD (+) $\mathrm{n}=11$ & \\
\hline Variables & $\mathrm{N}(\%)$ & $\mathrm{N}(\%)$ & $\mathrm{p}$-value \\
\hline Maternal AH & $7(22)$ & $1(9)$ & 0.66 \\
\hline Prenatal CTC & $30(96.7)$ & $11(100)$ & 1 \\
\hline Female & $18(58.1)$ & $7(63.6)$ & 1 \\
\hline Resuscitation & $6(19.3)$ & $6(54.5)$ & 0.049 \\
\hline HMD & $26(83.9)$ & $11(100)$ & 0.3 \\
\hline Surfactant & $8(25.8)$ & $9(81.8)$ & 0.003 \\
\hline Ventilatory assistance & & & \\
\hline IMV & $6(19.3)$ & $7(63.6)$ & 0.019 \\
\hline NIMV & $3(9.7)$ & $2(18.2)$ & 0.59 \\
\hline CPAP & $29(93.5)$ & $11(100)$ & 1 \\
\hline Sepsis & $4(12.9)$ & $3(27.3)$ & 0.35 \\
\hline PDA & $9(29)$ & $5(45.4)$ & 0.46 \\
\hline Methylxanthines & $21(67.7)$ & $11(100)$ & 0.041 \\
\hline & Mean (SD) & Mean (SD) & p-value \\
\hline GA & $30.2(1.73)$ & $29.3(2.5)$ & 0.17 \\
\hline Birth weight & $1349.1(323.6)$ & $1001.7(299.7)$ & 0.003 \\
\hline Z-score W & $-0.48(0.79)$ & $-0.49(0.83)$ & 0.12 \\
\hline Length & $37.9(3.4)$ & $34.2(3.7)$ & 0.009 \\
\hline Z-score C & $-0.33(1.2)$ & $-0.87(1.4)$ & 0.27 \\
\hline Head circumference & $27.2(2.1)$ & $25(2.9)$ & 0.021 \\
\hline Z-score HC & $-0.04(1.1)$ & $-0.37(1.8)$ & 0.54 \\
\hline Total O ${ }_{2}$ (hours) & $497.7(349.7)$ & $1466.7(598.6)$ & $<0.001$ \\
\hline Start of feedings (days) & $1.2(0.40)$ & 0.27 \\
\hline Full diet (days) & $14.2(6.1)$ & 0.058 \\
\hline
\end{tabular}




\begin{tabular}{|c|c|c|c|}
\hline \multirow{2}{*}{ NPT (days) } & \multirow{2}{*}{$\begin{array}{l}\text { BPD (-) n= } 31 \\
10.1(5.2)\end{array}$} & \multicolumn{2}{|c|}{ BPD (+) $n=11$} \\
\hline & & $13.4(6.3)$ & 0.108 \\
\hline \multicolumn{4}{|c|}{ BPD $(-)=$ Newborns without bronchopulmonary dysplasia } \\
\hline \multicolumn{4}{|c|}{ BPD $(+)=$ Newborns with bronchopulmonary dysplasia } \\
\hline \multicolumn{4}{|c|}{$\mathrm{AH}=$ Arterial Hypertension } \\
\hline \multicolumn{4}{|c|}{ CTC $=$ Corticoid } \\
\hline \multicolumn{4}{|c|}{ HMD = Hyaline Membrane Disease } \\
\hline \multicolumn{4}{|c|}{ IMV = Invasive Mechanical Ventilation } \\
\hline \multicolumn{4}{|c|}{ NIMV = Non-Invasive Mechanical Ventilation } \\
\hline \multicolumn{4}{|c|}{ PDA = Patent Ductus Arteriosus } \\
\hline \multicolumn{4}{|c|}{ SD $=$ Standard Deviation } \\
\hline \multicolumn{4}{|c|}{$\mathrm{GA}=$ Gestational Age } \\
\hline \multicolumn{4}{|l|}{ W = Weight } \\
\hline \multicolumn{4}{|l|}{$L=$ Length } \\
\hline \multicolumn{4}{|c|}{$\mathrm{HC}=$ Head Circumference } \\
\hline TPN = Total & trition & & \\
\hline
\end{tabular}

Although newborns with BPD had significantly higher REE in full-term CGA, we did not observe differences in body composition obtained in the plethysmography exam between the two groups. Newborns with BPD had lower Z-scores in the three anthropometric measurements in the full-term CGA than newborns without BPD, but without statistical significance (Table 2). 
Table 2

Comparison of growth, resting energy expenditure and body composition between newborns with and without bronchopulmonary dysplasia at term equivalent age

\begin{tabular}{|c|c|c|c|}
\hline & BPD $(-) n=31$ & BPD (+) $n=11$ & \\
\hline Variables & Mean (SD) & Mean (SD) & $\mathrm{p}$-value \\
\hline Z-score W & $-1.22(1.09)$ & $-1.47(1.29)$ & 0.91 \\
\hline Z-score L & $-1.33(1.06)$ & $-1.75(1.37)$ & 0.27 \\
\hline Z-score HC & $-0.37(0.93)$ & $-0.85(1.0)$ & 0.27 \\
\hline$\% \mathrm{FM}$ & $15.1(4.8)$ & $14.7(3.6)$ & 0.87 \\
\hline$\%$ LM & $84.9(4.8)$ & $85.3(3.6)$ & 0.8 \\
\hline FM (g) & 432 (222) & 419 (160) & 0.65 \\
\hline LM (g) & 2313 (393) & $2144(730)$ & 0.84 \\
\hline REE & $54.05(9.5)$ & $67.6(13.7)$ & 0.002 \\
\hline \multicolumn{4}{|c|}{ BPD $(-)=$ Newborns without bronchopulmonary dysplasia } \\
\hline \multicolumn{4}{|c|}{ BPD $(+)=$ Newborns with bronchopulmonary dysplasia } \\
\hline \multicolumn{4}{|l|}{ W = Weight } \\
\hline \multicolumn{4}{|l|}{$L=$ Length } \\
\hline \multicolumn{4}{|c|}{$\mathrm{HC}=$ Head Circumference } \\
\hline \multicolumn{4}{|c|}{$\% \mathrm{FM}=$ Percentage of Fat Mass } \\
\hline \multicolumn{4}{|c|}{$\% \mathrm{FFM}=$ Percentage of Lean Mass } \\
\hline \multicolumn{4}{|c|}{$\mathrm{FM}(\mathrm{g})=$ Fat Mass in grams } \\
\hline \multicolumn{4}{|c|}{ FFM = Lean Mass in grams } \\
\hline REE $=$ Restir & Energy Exper & & \\
\hline
\end{tabular}

Newborns with BPD received significantly more protein in the first week of life and had a lower calorie/protein ratio than newborns without BPD (Table 3). The NBs who developed BPD still showed significantly lower calorie/protein ratio in the second week of life, but with no difference in water, caloric, and macronutrient supply between the two groups. We did not observe differences between the two groups in the third and fourth weeks of life (Table 3) 
Table 3

Comparison of nutritional support received in the first 4 weeks between newborns with and without bronchopulmonary dysplasia

\begin{tabular}{|c|c|c|c|c|c|c|}
\hline & \multicolumn{3}{|c|}{ 1st week of life } & \multicolumn{3}{|c|}{ 2nd week of life } \\
\hline & $\begin{array}{l}\text { BPD }(-) n= \\
31\end{array}$ & $\begin{array}{l}\text { BPD }(+) n= \\
11\end{array}$ & & $\begin{array}{l}\text { BPD }(-) n= \\
31\end{array}$ & $\begin{array}{l}\operatorname{BPD}(+) n= \\
11\end{array}$ & \\
\hline Variables & Mean (SD) & Mean (SD) & $p$-value & Mean (SD) & Mean (SD) & $\mathrm{p}$-value \\
\hline WR & $117.3(8.4)$ & $115.8(5.3)$ & 0.73 & $152.3(17.8)$ & $143.9(10.8)$ & 0.07 \\
\hline CALR & $69.6(11.2)$ & $71.9(8.0)$ & 0.61 & $97.2(11.7)$ & $92.6(10)$ & 0.19 \\
\hline PTN & $2.8(0.8)$ & $3.4(0.2)$ & 0.002 & $3.2(0.5)$ & $3.4(0.3)$ & 0.53 \\
\hline LIP & $1.9(0.5)$ & $1.9(0.7)$ & 0.36 & $3.0(0.5)$ & $2.7(0.5)$ & 0.17 \\
\hline CARB & $9.7(1.3)$ & $9.4(1.6)$ & 0.52 & $14(2.4)$ & $13.1(2.7)$ & 0.29 \\
\hline \multirow[t]{3}{*}{ CAL/PTN } & $29(15.1)$ & $21.4(1.7)$ & 0.001 & 30.6 (3.2) & $27.5(2.6)$ & 0.012 \\
\hline & \multicolumn{3}{|c|}{ 3rd week of life } & \multicolumn{3}{|c|}{ 4th week of life } \\
\hline & $\begin{array}{l}\text { BPD }(-) n= \\
31\end{array}$ & $\begin{array}{l}\mathrm{BPD}(+) n= \\
11\end{array}$ & & $\begin{array}{l}\text { BPD }(-) n= \\
31\end{array}$ & $\begin{array}{l}\mathrm{BPD}(+) n= \\
11\end{array}$ & \\
\hline Variables & Mean (SD) & Mean (SD) & $p$-value & Mean (SD) & Mean (SD) & $\mathrm{p}$-value \\
\hline WR & $162.8(13.4)$ & $159.1(16.6)$ & 0.88 & $164.2(12.3)$ & $161.2(20.8)$ & 0.55 \\
\hline CALR & $108.9(10.9)$ & $106.2(11.8)$ & 0.59 & $109.4(14.3)$ & 109.9 (16.3) & 0.79 \\
\hline PTN & $3.4(0.4)$ & $3.4(0.4)$ & 0.73 & $3.4(0.6)$ & $3.3(0.6)$ & 0.76 \\
\hline LIP & $3.5(0.8)$ & $3.9(2.0)$ & 0.97 & $3.9(1.1)$ & $3.7(1.3)$ & 0.97 \\
\hline CARB & $15.5(1.8)$ & 15.9 (1.7) & 0.53 & $15.2(1.9)$ & $15.6(1.5)$ & 0.81 \\
\hline CAL/PTN & 31.9 (3.5) & 32 (4.9) & 0.78 & 33.3 (4.8) & 33.5 (3.9) & 0.83 \\
\hline \multicolumn{7}{|c|}{ BPD $(-)=$ Newborns without bronchopulmonary dysplasia } \\
\hline \multicolumn{7}{|c|}{ BPD $(+)=$ Newborns with bronchopulmonary dysplasia } \\
\hline \multicolumn{7}{|c|}{ SD = Standard Deviation } \\
\hline \multicolumn{7}{|c|}{ WR = Water Rate } \\
\hline \multicolumn{7}{|c|}{ CALR $=$ Calories Rate } \\
\hline \multicolumn{7}{|c|}{ PTN = Proteins } \\
\hline \multicolumn{7}{|c|}{ LIP = Lipids } \\
\hline $\mathrm{CARB}=\mathrm{Ca}$ & rates & & & & & \\
\hline
\end{tabular}


CAL/PTN = Calories/Proteins Ratio.

\section{Discussion}

The prevalence of BPD found is similar to that reported in the current literature [2, 25]. In this population, the REE was significantly higher in the term CGA in newborns who developed BPD. This finding corresponds to the reports of previous studies, which found a 20-30\% increase in energy expenditure in preterm NBs with BPD with more than four weeks of postnatal life [10-13].

Using the same instrument (Deltratac ${ }^{\circledR}$ II Metabolic Monitor), J Bauer et al. (2003) reported an increased energy expenditure of $50 \%$ from the third to the fifth week of life in NBs with BPD [13]. Using the same definition of BPD [19] used in our study, they found a mean energy expenditure in the third and fifth weeks of 80 and $102 \mathrm{kcal} / \mathrm{kg} /$ day, respectively, in preterm NBs with mild BPD, higher than those we found, but at different evaluation stages. In our population, even after the acute phase of the disease, preterm NBs with BPD maintained a higher REE than those without BPD.

The REE values in term CGA found in NBs with BPD ( $67.6 \mathrm{kcal} / \mathrm{kg} /$ day) is $20 \%$ above the values suggested by the American Academy of Paediatrics ( $50 \mathrm{kcal} / \mathrm{kg} /$ day) for healthy NBs, which is the benchmark in most NICUs for inferences of nutritional needs [26]. However, this higher REE was not reflected in the body composition of these NBs, as there was no difference between the volumes and proportions of lean and fat mass between the groups with and without BPD when reaching the CGA at term.

DeRegnier et al. (1996) studied NBs with very low birth weight and found a decrease in lean mass in 16 infants with BPD at one month of age, using anthropometric measurements and skinfolds, compared to 16 controls without BPD [7]. Huysman et al. (2003) followed a cohort of preterm infants under 30 weeks of GA who developed BPD up to the age of 12 months and reported a deficit in lean mass, using bioelectrical impedance, in children with BPD, compared to a population of reference of term children [8]. Later, in a prospective cohort with preterm NBs, less than 32 weeks of GA carried out in three maternity hospitals in Rio de Janeiro, evaluating growth and body composition by air displacement plethysmography in the 1-month CGA, Martins et al. (2018) did not observe differences between the NBs with and without BPD, both regarding the growth and body composition [9]. There was a difference of 15 to 20 years among these studies, and changes in nutritional practices used in NICUs may have influenced the results found. Since the publication of the Workshop Summary: nutrition of the extremely low birth weight infant [27], in 1999, a significant change was observed in the nutritional protocols of preterm NBs in the NICUs, with several publications related to improving the nutritional approach, with an early start of TPN and more significant protein and caloric intake in the first weeks of life $[28,29]$. 
Regarding growth, no difference was found between the NBs who developed and did not develop BPD. However, the small sample size did not allow the analysis of extreme preterm NBs separately. The nutritional protocol used in this NICU since 2016 follows the most recent recommendations [14-16]. In this cohort, the mean time of starting enteral feedings in NBs with and without DBP was 1.1 and 1.2 days, respectively. Besides the early onset of enteral diet, NBs with and without BPD received caloric and protein intake from the third and fourth weeks of life, very close to the recommended level, of 110-135 $\mathrm{kcal} / \mathrm{kg} /$ day and $3.5-4 \mathrm{~g} / \mathrm{kg} /$ day, respectively [14-16]. As a result, both groups received an average nutritional intake above 30 calories/gram of protein from the third and fourth weeks of life onwards. The administration of 30-40 calories/gram of protein is knowingly necessary to incorporate the administered protein for cell growth and not just for oxidation and energy production [30].

A limitation of our study was the small sample size, which does not allow stratification by GA, and as the results derive from a single unit, they cannot be generalized to other preterm populations. Another limitation is the lack of description of the NBs' caloric and protein intake in term CGA, which could influence the REE assessment. While this data was collected, it was not possible to analyse it, as a percentage of preterm NBs without BPD in the full-term CGA was evaluated after hospital discharge on breastfeeding and formula supplementation, underestimating the calculation of caloric and protein intake.

A strength of this study is the prospective assessment of macronutrients received by NBs, which allows a reliable assessment of nutritional intake in the first weeks of life, and the use of air displacement plethysmography, a non-invasive, reliable, and accurate method, the gold standard in the analysis of body composition in NBs and infants weighing up to $8 \mathrm{~kg}$. In conclusion, in this study, we observed that preterm NBs who developed BPD had higher REE in term CGA than those without BPD, without compromising body composition. We can assume that current nutritional approaches may be meeting the nutritional needs of this population.

\section{Abbreviations}

$A G A=$ adequate for gestational age

APGAR = vitality score at birth

$\mathrm{BPD}=$ bronchopulmonary dysplasia

$\mathrm{CGI}=$ corrected gestational age

$\mathrm{CPAP}=$ continuous positive airway pressure

$\mathrm{GA}=$ gestational age

$\mathrm{HC}=$ head circumference 
$\mathrm{HMD}=$ hyaline membrane disease

IFF/Fiocruz $=$ Fernandes Figueira National Institute of Women's, Child and Adolescent Health

IMV = invasive mechanical ventilation

$\mathrm{NB}=$ newborn

$\mathrm{NICU}=$ neonatal intensive care unit

NIMV = non-invasive mechanical ventilation

PDA = patent ductus arteriosus

REE $=$ resting energy expenditure

SGA $=$ small for gestational age

TPN $=$ total parenteral nutrition

\section{Declarations}

Funding:There was no funding for this research.

Conflicts of interest/Competing interests: The authors declare that they have no competing interests.

Availability of data and material: data will be available on request

Code availability: Not applicable

Authors' contributions:

Dr Lima PAT participated in the protocol development and in the data analysis, and had the primary responsability for patient screening, enrollment, outcome assessment, and writing the manuscript.

Dr Méio MDBB had primary responsibility for protocol development, supervised the design and execution of the study, the interpretation of the final data analyses and contributed to the writing of the manuscript.

Dr Moreira MEL participated in the analytical framework of the study, in the interpretation of the final data analyses and contributed to the writing of the study.

Abranches $A D$ and Dr Milanesi BG participated in the analytical framework of the study and contributed to the writing of the study.

Dr Gomes-Junior SCS performed the data analyses, in the interpretation of the final data analyses and contributed to the writing of the manuscript. 
Ethics approval: This study was approved by the Institution's Ethics Committee under Opinion $\mathrm{N}^{\circ} \mathrm{CAAE}$ 50243615.0.00005269.

Consent to participate: Newborns were only included in the study after the consent of the legal guardians who signed the Informed Consent Form.

Consent for publication: Not applicable

\section{Aknowledgements:}

None.

\section{References}

1. Stoll BJ, Hansen NI, Bell EF, Shankaran S, Laptook AR, Walsh MC, Hale EC, Newman NS, Schibler K, Carlo WA et al. for the Eunice Kennedy Shriver National Institute of Child Health and Human Development Neonatal Research Network (2010) Neonatal outcomes of extremely preterm infants from the NICHD Neonatal Research Network. Pediatrics 126:443-456. https://doi.org/10.1542/peds.2009-2959.

2. Bott L, Béghin L, Marichez C, Gottrand F (2006) Comparison of resting energy expenditure in bronchopulmonary dysplasia to predicted equation. Eur J Clin Nutr 60:1323-9. https://doi.org /10.1038/sj.ejcn.1602463.

3. Poindexter BB, Martin CR (2015) Impact of nutrition on bronchopulmonary dysplasia. Clin Perinatol 42:797-806. https:// doi.org /10.1016/j.clp.2015.08.007.

4. Rice MS, Valentine CJ (2015) Neonatal Body Composition: Measuring Lean Mass as a Tool to Guide Nutrition Management in the Neonate. Nutr Clin Pract 30:625-32. https:// doi.org/ $10.1177 / 0884533615578917$.

5. Ma G, Yao M, Liu Y, Lin A, Zou H, Urlando A, Wong WW, Nommsen-Rivers L, Dewey KG (2004) Validation of a new pediatric air-displacement plethysmograph for assessing body composition in infants. Am J Clin Nutr 79:653-60. https://doi.org/10.1093/ajcn/79.4.653.

6. Roggero P, Giannì ML, Amato O, Piemontese P, Morniroli D, Wong WW, Mosca F (2012) Evaluation of air-displacement plethysmography for body composition assessment in preterm infants. Pediatr Res 72:316-20. https://doi.org/ 10.1038/pr.2012.75.

7. de Regnier R-AO, Guilbert TW, Mills MM, Georgieff MK (1996) Growth Failure and Altered Body Composition Are Established by One Month of Age in Infants with Bronchopulmonary Dysplasia. J Nutr 126:168-75. https:// doi.org / 10.1093/jn/126.1.168.

8. Huysman WA, Ridder M de, Bruin NC de, Helmond G van, Terpstra N, Goudoever JBV, Sauer PJJ (2003) Growth and body composition in preterm infants with bronchopulmonary dysplasia. Arch Dis Child - Fetal Neonatal 88: F46-51. https://doi.org/ 10.1136/fn.88.1. f46.

9. Martins AS, Barbosa BMMD, Gomes SCS, Lima PAT, Milanesi BG, Moreira MEL (2018) Growth and body composition in preterm newborns with bronchopulmonary dysplasia: a cohort study. J Perinat 
Med 46(8). https://doi.org/10.1515/jpm-2018-0005.

10. Billeaud C, Piedboeuf B, Chessex P (1992) Energy expenditure and severity of respiratory disease in very low birth weight infants receiving long-term ventilatory support. J Pediatr 120:461- 4. https://doi.org/10.1016/s0022-3476(05)80921-7.

11. Wahlig MT, Gatto CW, Boros SJ, Mammel MC, Mills MM, Georgieff MK (1994) Metabolic response of preterm infants to variable degrees of respiratory illness. J Pediatr 24:283- 8.

https://doi.org/10.1016/s0022-3476(94)70321-3.

12. DeMarie MP, Hoffenberg A, Biggerstaff SL, Jeffers BW, Hay Jr WW, Thureen PJ (1999) Determinants of energy expenditure in ventilated preterm infants. J Perinat Med 27:465- 72. https://doi.org/ 10.1515/JPM.1999.062.

13. Bauer J, Maier K, Muehlbauer B, Poeschl J, Linderkamp O (2003) Energy expenditure and plasma catecholamines in preterm infants with mild chronic lung disease. Early Hum Dev 72:147-57. https://doi.org/ 10.1016/s0378-3782(03)00046-x.

14. van Goudoever JB, Carnielli V, Darmaun D, Sainz de Pipaon M, ESPGHAN/ESPEN/ESPR/CSPEN working group on pediatric parenteral nutrition ESPGHAN/ESPEN/ESPR/CSPEN guidelines on pediatric parenteral nutrition: amino acids. Clin Nutr 2018, 37:2315-2323. https://doi.org/10.1016/j.clnu.2018.06.945.

15. Mesotten D, Joosten K, van Kempen A, Verbruggen S, ESPGHAN/ESPEN/ESPR/CSPEN working group on pediatric parenteral nutrition (2018) ESPGHAN/ESPEN/ESPR/CSPEN guidelines on pediatric parenteral nutrition: carbohydrates. Clin Nutr 37: 2337-2343. https://doi.org/10.1016/j.clnu.2018.06.947

16. Joosten K, Embleton N, Yan W, Senterre T, ESPGHAN/ESPEN/ ESPR/CSPEN working group on pediatric parenteral nutrition (2018) ESPGHAN/ESPEN/ESPR/CSPEN guidelines on pediatric parenteral nutrition: energy. Clin Nutr 37:2309-2314. https://doi. org/10.1016/j.clnu.2018.06.944.

17. Klevebro S, Westin V, Sjöström ES, Norman M, Dornellöf M, Bonamy A-KE, Hallberg B (2019) Early energy and protein intakes and associations with growth, BPD, and ROP in extremely preterm infants. Clinical Nutrition 38:1289-1295. https://doi.org/ 10.1016/j.clnu.2018.05.012.

18. Milanesi BG, Lima PAT, Villela LD, Martins AS, Gomes-Junior SCS, Moreira MEL, Méio MDBB (2021) Assessment of Early nutrition intake in preterm infants with bronchopulmonary dysplasia: a cohort study. Eur J Pediatr 180:1423-1430. https://doi.org/ 10.1007/s00431-020-03912-0.

19. Jobe AH, Bancalari E (2001) Bronchopulmonary dysplasia. Am J Respir Crit Care Med 163:1723-9. https://doi.org/ 10.1164/ajrccm.163.7.2011060.

20. Weir JB (1949) New methods for calculating metabolic rate with special reference to protein metabolism. J Physiol 109:1-9. https://doi.org/10.1113/jphysiol. 1949.sp004363.

21. WHO.Thermal protection of the newborn: a practical guide. Geneva: World Health Organization. 1997. p. 17-22.

22. Moreira MEL, Vieira AA, Mendes Soares FV, Bastos Lopes R, Gomes P, Abranches AD, Lopes JMA (2007) Determining the least time required for measuring energy expenditure in premature neonates. 
J Perinat 35:71-5. https://doi.org/ 10.1515/JPM.2007.011.

23. Fenton TR, Kim JH (2013) A systematic review and meta-analysis to revise the Fenton growth chart for preterm infants. BMC Pediatr 13:59. https://doi.org/ 10.1186/1471-2431-13-59.

24. Zin OA, Soares FVM, Abranches AD de, Costa ACC da, Villela LD, Moreira MEL (2019) Analysis of the differences between the prescribed and the administered diet to preterm infants using an electronic too. Rev Paul Pediatr 37:472-8. https://doi.org/10.1590/1984-0462/,2019,37,4,00008.

25. Shah PS, Lui K, Sjörs G, Mirea L, Reichman B, Adams M, Modi N, Darlow BA, Kusuda S, Feliciano LS et al. (2016) Neonatal Outcomes of Very Low Birth Weight and Very Preterm Neonates: An International Comparison. J Pediatr 177:144-152.e6. https://doi.org/ 10.1016/j.jpeds.2016.04.083.

26. American Academy of Pediatrics, Committee on Nutrition. Nutritional needs of the preterm infant. In: Kleinman RE, editor. Pediatric nutrition handbook. 6th ed. Elk Grove Village/IL: American Academy of Pediatrics, 2009. p. 79-112.

27. Hay WW, Lucas A, Heird WC, Ziegler E, Levin E, Grave GD, Catz CS, Yaffe SJ (1999) Workshop summary: nutrition of the extremely low birth weight infant. Pediatrics 104:1360-8. https://doi.org/ 10.1542/peds.104.6.1360.

28. Agostoni C, Buonocore G, Carnielli VP, De Curtis M, Darmaun D, Decsi T, Domellöf M, Embleton ND, Fusch C, Genzel-Boroviczeny O, et al. (2010) Enteral nutrient supply for preterm infants: commentary from the European Society of Paediatric Gastroenterology, Hepatology and Nutrition Committee on Nutrition. J Pediatr Gastroenterol Nutr 50:85-91. https://doi.org/ 10.1097/MPG.0b013e3181adaee0.

29. Ehrenkranz RA, Das A, Wrage LA, Poindexter BB, Higgins RD, Stoll BJ, Oh W (2011) Early nutrition mediates the influence of severity of illness on extremely LBW infants. Pediatr Res 69:522-9. https://doi.org/ 10.1203/PDR.0b013e318217f4f1.

30. Embleton ND, Akker CHP (2019) Protein intakes to optimize outcomes for preterm infants. Semin Perinatol 43:151-154. https://doi.org/ 10.1053/j.semperi.2019.06.002.

\section{Figures}




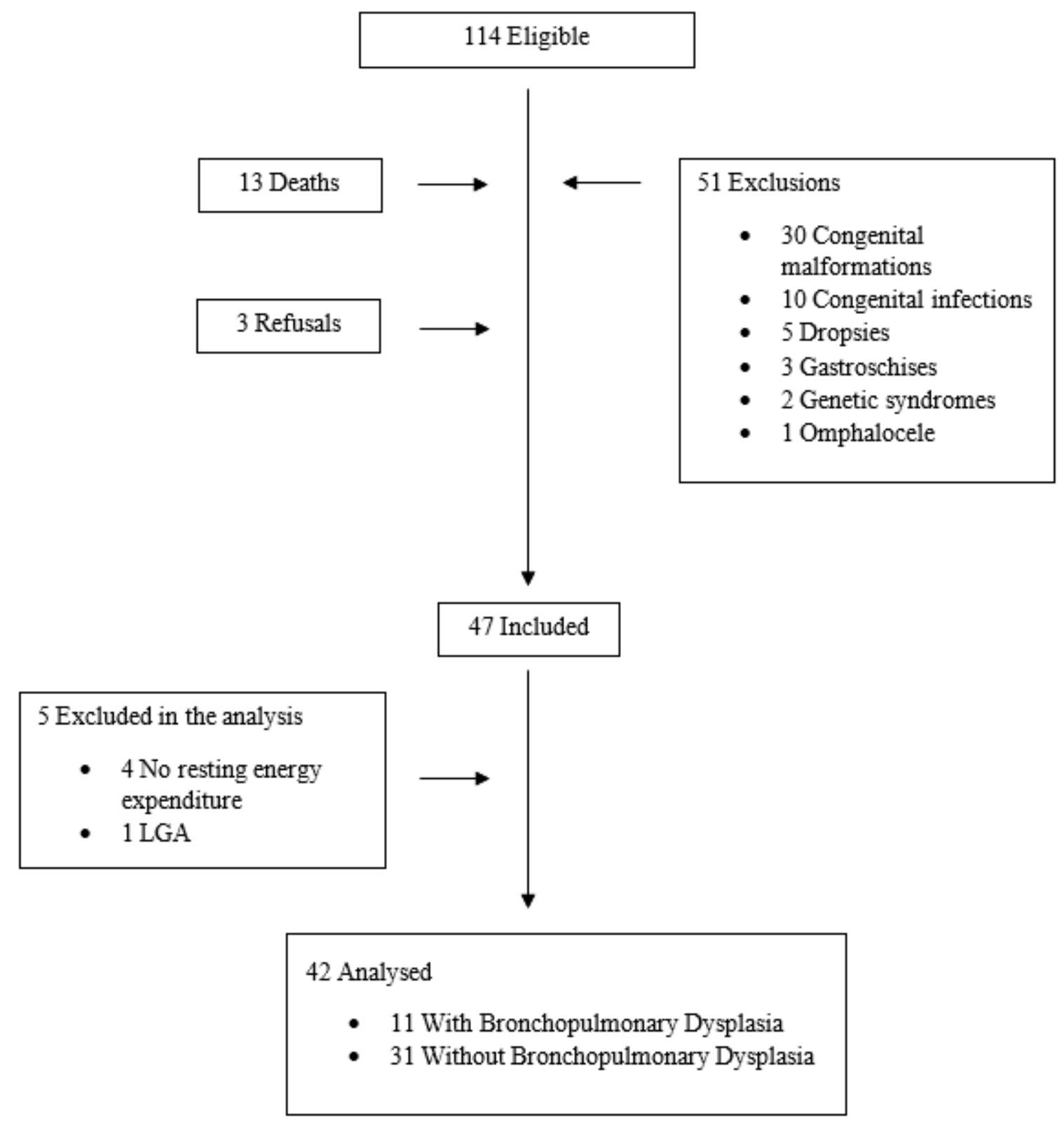

Figure 1

Study Population Flowchart 